\title{
INFLUENCE OF SILICA NANOPARTICLES ON THE PROPERTIES OF CELLULOSE COMPOSITE MEMBRANES: A CURRENT REVIEW
}

\author{
KHAYELIHLE DLOMO, SAMSON M. MOHOMANE and TSHWAFO E. MOTAUNG \\ Department of Chemistry, University of Zululand, Kwadlangezwa, South Africa \\ 区 Corresponding author: T. E. Motaung, motaungt@unizulu.ac.za
}

Received November 12, 2019

\begin{abstract}
Cellulose has lately gained much attention in its use as membrane due to the fact that it is cheap and has the potential to remove dissolved ions and organic contaminants. This is despite the fact that cellulose suffers from lack of reactive functional groups, as well as poor thermal and chemical resistance. The incorporation of silica $\left(\mathrm{SiO}_{2}\right)$ into cellulose membranes offers design flexibility, permeation performance, durability improvement, thermal stability and enhances its surface hydrophilicity. Cellulose membranes further exhibit improved mechanical performance, when the silica is uniformly dispersed at very low filler concentration. This study aims to review the incorporation of silica in cellulose nanocomposites for potential usage in water filtration membranes. The study further overviews the synthesis and modification of silica nanocomposites using various methods and processes.
\end{abstract}

Keywords: cellulose, silica, membranes, nanocomposites

\section{INTRODUCTION}

The interest in using metal oxides as reinforcing fillers in the development of polymer nanocomposite materials is constantly growing. The addition of metal oxides typically results in water permeation, and mechanically and thermal stability improvements. All these improvements are normally achieved at very low filler contents (usually $<5 \mathrm{wt} \%$ ). ${ }^{1-3}$ As a result, nanocomposites become promising for new applications, as sensors, in non-linear optics and nano-wires, amongst others. Nanocomposites also offer various benefits, such as low density, low cost, high transparency, high accessibility, good flow, better surface properties, easy fabrication, flammability resistance and high magnetic performance. ${ }^{4}$ Nanocomposites can be produced by the same processes and methods that are used to produce conventional polymer composites. However, a correct selection of the preparation technique is essential to obtain a material with the desired properties. The filler and matrix interface is also a key factor that defines the final properties of the nanocomposites, depending on the dispersion and surface properties..$^{5-7}$

Silica $\left(\mathrm{SiO}_{2}\right)$ has been widely used as a ceramic filler in the development of nanocomposites due to its easy synthesis and surface properties. Silica particles are normally extracted from natural resources containing other metal impurities, which may not be favourable for advanced industrial applications. Natural mineral silica includes quartz, flint, tridymite or cristobalite, and typically exists in crystalline form. Another form is amorphous silica, such as colloidal silica, silica gel and precipitated silica. ${ }^{5-7}$ There are two approaches that are generally used to obtain silica particles: top-down and bottom-up approaches. The top-down approach is a physical method that consists in reducing the original size of silica by using special size-reducing techniques. The bottom-up one involves chemical agglomeration from atom to atom or molecule to molecule, making up the silica nanoparticle. The most commonly used methods to synthesize silica nanoparticles are the sol-gel process, reverse microemulsion and flame synthesis. Silica has found potential applications in various fields, such as catalytic supports, sensors, optical hosts, sorption media and water treatment, amongst others. Many applications require silica particles with a narrow size distribution, controlled size, shape, and surface properties. ${ }^{8-10}$

Cellulose is the main constituent of biomass, forming approximately $40 \%$ to $45 \%$ of the dry 
substance in most lignocellulosic materials. Cellulose is a linear, unbranched homopolysaccharide composed of anhydroglucose units, which are linked together by $\beta-1,4$-glycosidic bonds to form a crystalline material. Native cellulose consists of highly ordered crystalline regions, along with disordered amorphous regions. Alkaline treatment or mercerization is one of the most frequently used chemical methods for the isolation of cellulose from natural fibers. ${ }^{11-13}$

Membranes have been used for more than 45 years for water treatment, using a wide range of materials, such as polymeric and ceramic based materials. Ceramic membranes are mostly used because they are thermally and chemically stable, have a longer life span and high porosity. Despite their popularity, they are quite expensive and brittle. On the other hand, polymer membranes are cheaper, offer design flexibility and potential for removing dissolved ions and organic contaminants. ${ }^{14}$ However, polymer membranes also have some drawbacks, including low mechanical strength, low flux and hydrophobicity. Most reviews on the literature based on polymer composite membranes have focused on the use of synthetic polymers over natural polymers, such as cellulose. ${ }^{15-16}$ Despite this, cellulose has gained much attention lately in its use as membrane due to the fact that it is cheaper, hydrophilic, porous, semipermeable and offers good transport characteristics. However, cellulose suffers from poor thermal and chemical resistance, lack of reactive functional groups and fouling issues.

Cellulose acetate (CA) and nitrocellulose have been utilized in separation membranes for water treatment due to their effectiveness and environmental friendliness. Particularly, CA has been regarded as one of the best membrane materials in the field of reverse osmosis, ultrafiltration and gas permeation. CA is suitable as membrane due to its moderate salt rejection and good film forming properties. These membranes are easy to manufacture, cost effective and are environmentally friendly.
Despite all these advantages, CA and its derivatives have low oxidation properties, poor resistance, poor mechanical strength, and can only be used at limited temperature (maximum $30^{\circ} \mathrm{C}$ ). Therefore, the incorporation of $\mathrm{CA}$ with metal oxides, such as silica, has gained momentum lately. The performance of the material is notably influenced by its constituents, which remarkably influence the properties, such as surface hydrophilicity and water permeability. ${ }^{17-20}$

Metal oxides, including silica, have been used in ceramic and polymeric membranes to enhance various properties of the membrane surface. In a study, Abedini et al. ${ }^{21}$ fabricated a mixed matrix membrane that consisted of one layer of titanium $\left(\mathrm{TiO}_{2}\right)$ dispersed throughout a natural polymer matrix. The incorporation of $\mathrm{TiO}_{2}$ nanoparticles onto the CA membrane enhanced the water permeation and thermal stability. A polymeric membrane often offers low cost production due to cheaper raw material, but then suffers from low water permeability, which makes it less likely to be used in water treatment. The modification or addition of silica nanoparticles to the polymeric membrane increased the hydrophilicity and permeation performance of the membrane. ${ }^{22}$ This study aims to review the influence of silica addition on the properties of cellulose nanocomposites for potential usage in water filtration membranes.

\section{CELLULOSE}

Cellulose can be defined as a linear homopolymer composed of $\beta$-D-glucopyranose units, which are linked together by $\beta$-glycosidic bonds (Fig. 1). The native cellulose molecule has a length of at least $5000 \mathrm{~nm}$, which corresponds to a chain of about 10000 glucopyranose units. The degree of polymerization of cellulose depends on the source of cellulose and the extraction method, and ranges between 1000 to 30000 units. $^{23-24}$ Cellulose molecules are aggregated by secondary $\mathrm{OH}$ groups through van der Waals forces and both intra- and intermolecular hydrogen bonds. ${ }^{25}$

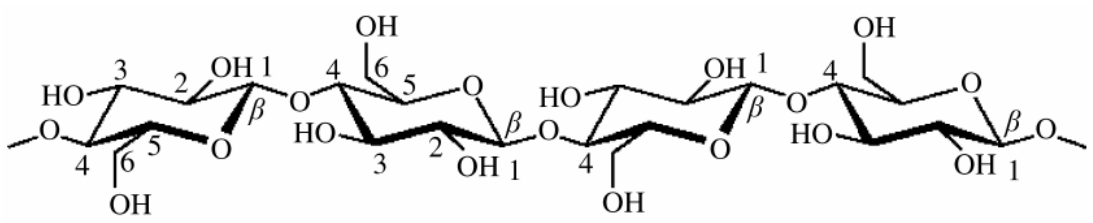

Figure 1: Position of hydroxyl groups on cellulose backbone 


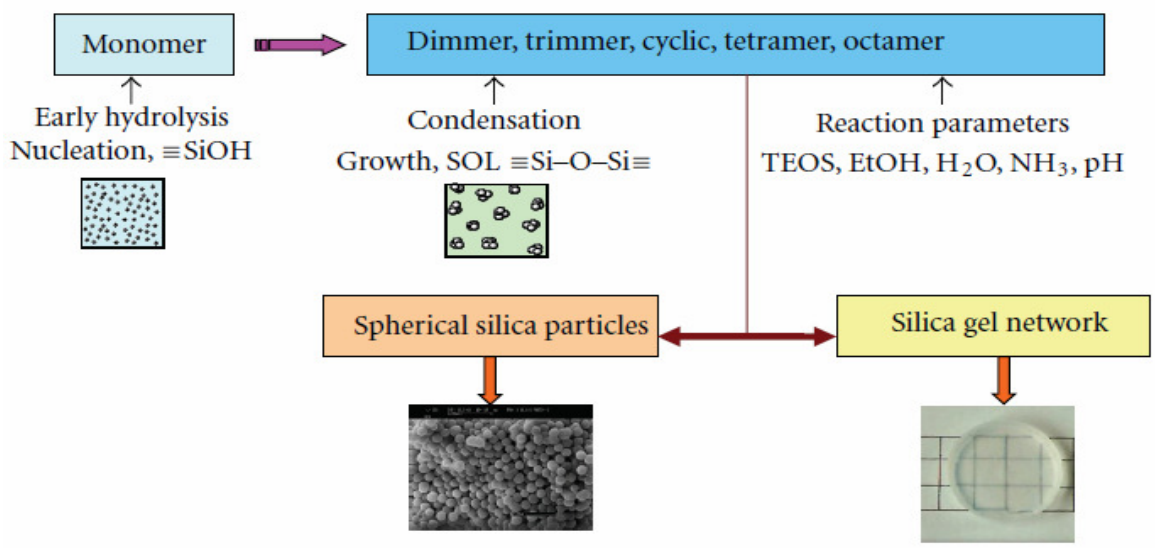

Figure 2: Schematic representation of silica production by sol-gel process

In order to modify the cellulose structure, its highly ordered hydrogen-bonded lattice must be deformed or disrupted by dissolution or swelling. ${ }^{26}$

Cellulose is very reactive with water and has strong affinity to materials containing hydroxyl functional groups. It is also very stable to different solvents and can only be dissolved in the presence of strong acids or strong hydrogen; its glass transition temperature $\left(200-230{ }^{\circ} \mathrm{C}\right)$ is close to its thermal decomposition temperature -260 ${ }^{\circ} \mathrm{C} .{ }^{27}$ Moreover, Yamane et $\mathrm{al}^{28}$ reported regenerated cellulose to be the most hydrophilic polymer due to its high density of hydroxyl groups, which makes it a good choice in the application in filtration membranes.

\section{Cellulose composite membranes}

The fabrication of membranes for water filtration using cellulose has been overlooked since the 1960s. This is despite the potential of CA membrane to remove viruses, pesticides, bacteria, oil, heavy metals, dyes etc. ${ }^{29}$ Additives, such as bentonite, ${ }^{30}$ modified coal, ${ }^{31}$ and sodium dodecyl sulphate, ${ }^{32}$ have been incorporated into cellulose to increase the water permeability of the membrane and its surface porosity. Carbon nanotubes $(\mathrm{CNTs})^{33}$ and metal oxides ${ }^{34-37}$ have been used as additives to improve the durability, thermal stability, and mechanical performance of cellulose membranes. ${ }^{7}$ Moreover, metal oxides, such as $\mathrm{AgO}_{2}{ }^{38} \mathrm{TiO}_{2}{ }^{39}$ and $\mathrm{ZnO},{ }^{40}$ are used in polymeric membranes due to their antimicrobial and photocatalytic properties. In addition, metal oxides improve the stability of membranes, permeability and porosity. CNTs cellulose-based membranes are also used due to their excellent antibacterial properties. Their unique property, as compared to metal oxide membranes, is that they can kill bacteria once they come in contact with active sites, which are located in the cellulose membrane. Despite all the advantages of CNTs leading to promising antibacterial performance of membranes, some limitations of CNTs in cellulose membranes arise with their toxicity, high cost, poor dispersion and length of alkyl group. ${ }^{41-42}$

\section{SILICA NANOPARTICLES}

There are three common methods reported in the literature for synthesizing silica nanoparticles: flame synthesis, reverse emulsion and sol-gel method. In the flame synthesis method, silica nanoparticles are produced through high temperature flame decomposition of metalorganic precursors. This process is sometimes referred to as chemical vapour condensation (CVC) and proceeds by reacting silicon tetrachloride $\left(\mathrm{SiCl}_{4}\right)$ with hydrogen and oxygen. This method is associated with difficulties in controlling the particle size, morphology and phase composition. ${ }^{43-45}$ In the reverse emulsion method, the surfactant molecules are dissolved in organic solvents and spherical micelles. The disadvantages associated with reverse emulsion are the high cost and difficulties in the removal of surfactants from the final products. ${ }^{46}$ The sol-gel method has been widely used to produce silica nanoparticles due to its ability to form a pure and homogeneous product under mild conditions. This process involves hydrolysis and condensation of metal alkoxides, such as tetraethylorthosilicate (TEOS), $\mathrm{Si}\left(\mathrm{OC}_{2} \mathrm{H}_{5}\right)_{4}$ or inorganic salts, such as sodium silicate $\left(\mathrm{Na}_{2} \mathrm{SiO}_{3}\right)$ in the presence of acid, e.g. hydrochloric acid $(\mathrm{HCl})$, or base, e.g. $\left(\mathrm{NH}_{3}\right)$, as a catalyst (Fig. 2). ${ }^{47-50}$ 
There are two models used to describe the growth mechanism of silica: monomer addition and controlled aggregation. In the monomer addition, the particle growth occurs by the addition of hydrolysed monomers, which is the primary particle surface. Meanwhile, in the aggregation model, the nucleation occurs continuously throughout the reaction and the resulting primary particle aggregate forms dimmer, trimmer and larger particles (secondary particles). Both methods lead to the formation of spherical or gel network silica particles, depending on the reaction parameters. ${ }^{51-52}$ Spherical and monodispersed silica particles were achieved in a study by Stober et al. ${ }^{53}$ Furthermore, the optimization conditions play a vital role in the sol-gel method to produce the smallest, homogenous and monodispersed silica particles. These nanoparticles are produced by slowing down the rate of the polycondensation reaction by controlling the reaction parameters. Most researchers also revealed that increasing ammonia concentration increases the particle size of silica. Figure 3 reflects different sizes of silica particles produced by controlling the reaction parameters. Small amounts of ammonium salts $(\mathrm{Br}, \mathrm{I}$ and $\mathrm{Cl}$ ) enable the production of monodispersed silica particles of 20-34 nm, depending on the anion used. All the anions showed great effectiveness in reducing particle size by $73-78 \%$.

Drying and agglomeration is another critical step in producing powdered silica nanoparticles. The most common techniques used to produce solid materials from liquid phase are freeze drying, supercritical drying, spray drying and thermal drying. A consistent controlled drying process results in the formation of dispersed particles, while drying in the presence of water leads to agglomeration. ${ }^{54} \mathrm{~A}$ big challenge rises in the production of highly dispersed nanoparticle powders that are strongly sensitive to processing conditions. Such preparation of silica polymer nanocomposites in the presence of agglomerated silica particles can minimize the reinforcement effect, resulting in reduced thermal and chemical properties. The strength of the agglomerate largely depends on the solubility of the nanoparticles. In addition, the agglomeration behaviour is influenced by capillary drag and the hydrodynamic effect during the drying process. Consequently, the agglomeration of nanoparticles could be reduced by the use of ethanol as suspension medium during the drying process. ${ }^{55}$ Rahman and his team ${ }^{56}$ explained that the effect of freeze drying, dehydration using alcohol and drying in the oven is based on size distribution, dispersion and agglomeration of silica nanoparticles. The results of the study showed that dehydration using alcohol is a reproducible technique to produce silica nanoparticles with improved dispersion and reduced agglomeration.

\section{Surface modification of silica}

Silica particles contain hydroxyl groups on their surface called silanols, which are hydrophilic and have many reactive sites. These functional groups are essential for some specific properties of composite materials, such as hydrophilicity, hydrophobicity, chemical binding ability etc. ${ }^{57-59}$ In most cases, nano-sized inorganic particles with hydrophilic hydroxyl bonding network lead to irregular agglomerations. This makes it difficult for inorganic oxide fillers to disperse very well into the polymer matrix, which eventually leads to poor compatibility with the organic polymer. The polymer composites exhibit good performance when the silica fillers are uniformly dispersed in the polymer matrix. Hence, surface modification of silica particles is crucial for their application in polymer composites. ${ }^{60-63}$

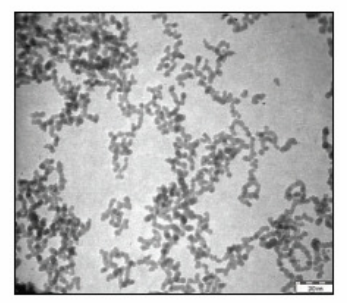

(a)

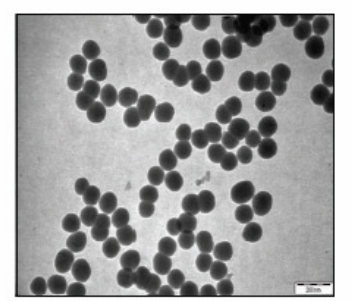

(b)

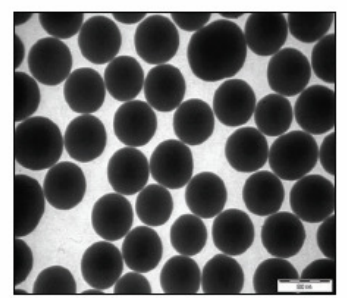

(c)

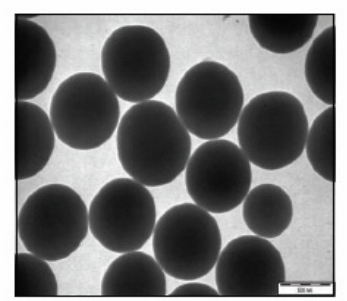

(d)

Figure 3: Size distribution of silica particles obtained by controlling reaction parameters: (a) $\sim 21 \mathrm{~nm}$, (b) $\sim 131 \mathrm{~nm}$, (c) $\sim 369 \mathrm{~nm}$, and (d) $\sim 565 \mathrm{~nm}$ 


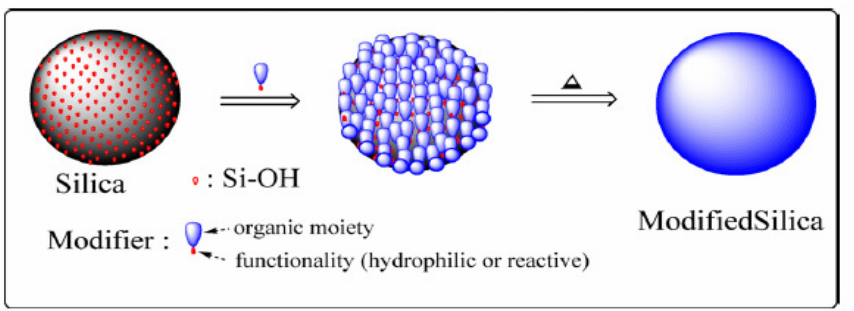

Figure 4: Silica particle surface altered with a modifier

The silanols on the surface of silica particles can be modified physically by physisorption or chemically by covalent bonding, as shown in Figure 4 . The physisorption modification method is associated with thermal instability because of weak hydrogen bonding or van der Waals forces interaction between the two phases. The condensation reaction is an alternative approach of modification using an organic polymer and the silica filler, involving functionalized polymers and alkoxysilane precursors. This method results in the formation of chemical bonds between the polymer and the silica filler, and is recommended to increase the interfacial stability between the silica filler and the polymer matrix. ${ }^{64-68}$ Surface modifications have been reported to enhance the affinity and dispersion between an inorganic filler and an organic polymer. ${ }^{69-71}$

Silane coupling agents $\left(\mathrm{Si}(\mathrm{OR})_{3}\right)$ are primarily used for the modification of the silica surface. They have the ability to bond inorganic materials, such as silica nanoparticles, with an organic polymer. Basically, the $\mathrm{Si}(\mathrm{OR})_{3}$ portion reacts with the silica nanoparticle, while the organofunctional group (R) reacts with the polymer. There are some common silane coupling agents used for surface modification of silica: vinyltriethoxysilane (VTS), methacryloxypropyltrimethoxysilane (MPTS), chloropropyltriethoxysilane (CPTS) etc. The chemical modification of the silica surface using silane coupling agents proceeds in either aqueous or non-aqueous medium, known as postmodification. The postmodification is usually used for grafting aminopropyltrimethoxysilane (APTS) molecules onto the silica surface. The aqueous system is favorable for large-scale production, so that silanes undergo hydrolysis and condensation before deposition on the surface. Sun and his team ${ }^{72}$ investigated the effect of surface modification on the dispersion of silica nanoparticles for potential application as semiconductors in packaging. They activated the surface of silica nanoparticles using two types of silane groups: aminoethylaminopropyltriethoxysilane (AEAPTS) and 3glycidyloxypropyltriethoxysilane (GPTS), carrying amino and epoxy groups. Other coupling agent, such as APTES and TEOS, are used to modify silica through a one-pot sol-gel procedure, with potential application in the biomedical field in drugs, DNA and carriers of enzymes. ${ }^{73-74}$

\section{SILICA/CELLULOSE NANOCOMPOSITES Mechanical properties}

Reddy et $a .^{75}$ investigated the mechanical properties of regenerated cellulose reinforced with silica nanoparticles. The results showed an increase in tensile strength and modulus at low concentration of silica. The improvement in mechanical properties was attributed to good dispersion of silica in the regenerated cellulose. At high concentration, the silica particles were agglomerated in the polymer matrix, negatively affecting the mechanical properties. Song et al. ${ }^{76}$ Ashori et $a l^{77}$ and Xie et al. ${ }^{78}$ also reported an increase in mechanical properties at low silica loadings, investigating various nanocomposite materials reinforced with silica. Arthanareeswaran et $a l .{ }^{79}$ examined the effect of silica particles on CA blend membranes, with silica contents from 0 to $40 \%$ by weight. The mechanical properties (tensile strength, tensile stress and elongation at break) of the $\mathrm{CA} /$ silica composites increased initially and decreased with further addition of silica above $10 \mathrm{wt} \%$. This trend was associated with silica agglomeration, which resulted in suppression of microvoids and poor interaction between the polymer and the inorganic filler. Similar observations have been reported by Ahmad et al., ${ }^{17}$ who investigated the effect of silica addition on the mechanical properties of membranes prepared with $\mathrm{CA}$ and polyethylene glycol. The results showed an increase in Young's 
modulus, tensile strength and elongation at break with the addition of silica nanoparticles, as compared to the neat $\mathrm{CA}$ /polyethylene glycol membranes. At high silica concentration above $4 \%(\mathrm{w} / \mathrm{v})$, large phase separations were observed because of the excessive concentration of silica, which resulted in a decline of mechanical properties.

$\mathrm{Wu}$ et $a l .{ }^{80}$ investigated the mechanical properties of cellulose/silica aerogel nanocomposites by compression stress and strain tests. The results showed that the cellulose/silica aerogel at higher silica content $(79 \%)$ cracked at low strain (20\%) when undergoing an increased external pressure. In a study by Wojciechowska $e t$ $a l .{ }^{81}$ the nanocomposites of $\mathrm{CA}$ butyrate and TEOS prepared via the sol-gel method exhibited better mechanical properties than those of unmodified CA butyrate. The improvements were associated with good interfacial adhesion and enhanced efficiency of the stress transfer mechanism between the two components. Moreover, the neat $\mathrm{CA}$ butyrate exhibited the highest value of elongation at break (increased by $28 \%$ ), compared to the modified CA butyrate/silica nanocomposites. In another study by Ibrahim et al., ${ }^{82}$ the authors reported an enhancement of mechanical properties (burst, short span and tensile strength) at low silica concentration. Above $4 \mathrm{wt} \%$ silica, the roughness and elongation at break decreased owing to agglomeration of silica nanoparticles in certain spots across the hybrid.

\section{Morphological properties}

Morphological studies make it possible to clearly observe the phase morphology and interfacial adhesion of silica/cellulose composites. Nevertheless, it is necessary to control the morphological structure of the membrane to attain high performance membranes for targeted applications. $^{18}$ Neto et al. ${ }^{83}$ investigated the morphological properties of silica/cellulose nanocomposites prepared using two distinct methodologies: deposition of silica nanoparticles on cellulosic fibres via polyelectrolytes (Layerby-Layer approach, $\mathrm{LbL}$ ) and in situ synthesis of silica in the presence of cellulosic fibres. Both methods were able to produce silica/cellulose nanocomposites and their morphological properties were strongly dependent on the synthetic method employed. The LbL technique yielded discrete and well-defined $\mathrm{SiO}_{2}$ nanoparticles on the surface of cellulosic fibres.
The result was due to the balanced interaction that occurred between the silica coating and the polyelectrolyte. Meanwhile, the in situ synthesis yielded homogeneously coated $\mathrm{SiO}_{2}$ /cellulose nanocomposites due to the condensation of silica oligomers during the growth process and ammonia concentration, which dispersed the silica particles, allowing them to be adsorbed homogeneously.

The fractured surface of cellulose/silica hybrids was extremely rough, as compared to that of neat cellulose, as found in the studies of Reddy et $a l^{75}$ and Song et $a l^{76}$ Morphological studies showed that silica nanoparticles were homogeneously dispersed with no aggregation, indicating good interfacial interaction. However, the composite films with $5 \mathrm{wt} \%$ nanosilica showed a rough surface, with some aggregation of nanosilica. In another study, Arthanareeswaran et $a l^{79}$ manipulated the morphological structure of $\mathrm{CA}$ to attain a better performance of the membrane by incorporating nanosilica. The SEM results revealed that the top surface of pure cellulose was smooth and contained small size pores. However, a drastic increase of $\mathrm{SiO}_{2}$ content up to $40 \mathrm{wt} \%$ increased the number of pores and visibly increased the pore density on the top surface of the membrane. Similar results were also reported by Ashori et al. ${ }^{77}$ showing strong interfacial adhesion between bacterial cellulose fibres and nanosilica particles, without noticeable aggregates observed by SEM.

Raabe et $a l^{84}$ and Barud et al. ${ }^{85}$ performed morphological analyses and showed welldeposited silica nanoparticles embedded in the cellulosic fibers interspace in their studies. This was caused by the hydrolysis of TEOS precursor, followed by the condensation of resultant hydroxyl groups on the surface of cellulosic fibres. When TEOS was added, the silica nanoparticles overcast the cellulosic fibres, showing strong affinity between the inorganic filler and the polymer matrix. This eventually highlights that high concentration of TEOS had a significant effect on the size and morphology of silica nanoparticles in the final composites. Another study revealed successful functionalization of cellulose fibres with TEOS precursor by the sol-gel method. The properties attained included reduction of water uptake and enhancement of mechanical strength due to strong chemical interaction between the silica and cellulose phases. ${ }^{86}$ 
Meer et al..$^{87}$ investigated the impact of the $\mathrm{pH}$ value of the base catalysis on the condensation speed and amount of silica nanoparticles deposited on the CNF matrix via sol-gel synthesis using TEOS as precursor. A higher $\mathrm{pH}$ value (12) made it easier and faster to form silica nanoparticles in the matrix. Similar findings were also reported by Ghiorghita et al., ${ }^{88}$ who investigated a novel silica/polyelectrolyte multilayer core-shell composite with selectivity for anionic dyes. The authors attributed the higher number of amino groups present to the higher amount of polycation deposited when the polymer concentration is higher. Selakjani et al. ${ }^{89}$ evaluated the effect of silica in a cellulose nanocomposite through electrostatic interaction to reinforce polysulfone membranes. Their SEM results showed that silica was well dispersed on the surface of the cellulose fibers in the form of spherical nanoparticles and no apparent agglomeration was observed during the doping process. This was attributed to the micelle effect of sodium dodecyl sulfate surfactant, which led to good dispersion of the particles.

\section{Water related properties}

Ahmad et $a l .{ }^{17}$ prepared a series of cellulose/polyethylene glycol-600 membranes via the phase inversion method. The five highest salt rejection membranes were selected and modified with varying amounts of silica. The results showed a decreasing and increasing trend in contact angle and flux rate, respectively, with increasing the silica particle concentration (Fig. 5). These results clearly showed that silica particles can improve the hydrophilicity of the membrane. Similar observations were obtained by
Song et $a l .^{76}$ and Muhamad et al. ${ }^{90}$ using polysulfone (PSF) and polyethersulfone (PES) as matrices. Both studies indicated that the addition of silica from 1-4 wt\% in various matrices improved the hydrophilicity property of the membrane. Abedini et al. ${ }^{21}$ and Arthanareeswaran et $a l .^{79}$ revealed an increase in membranes water content with the incorporation of $\mathrm{TiO}_{2}$ and silica nanoparticles in their studies, respectively. Both studies suggest that metal oxide nanoparticles create pore spaces in the polymer matrix, which leads to an increase in water content. The results of these studies were supported by the findings of Pinto et al. ${ }^{81}$ who revealed that the water content and permeability increased with an increase in the amount of silica.

Reddy et $a l^{75}$ evaluated the water related properties (water vapour permeability (WVP), moisture content and contact angle) of regenerated cellulose (RC)/nanosilica composite films, compared to neat RC films. The results showed a decrease in WVP and water absorption with an increase in the nanosilica content (up to 2 wt $\%$ ). Moreover, the contact angle decreased with the increment in the silica content due to the formation of strong bonds between the nanosilica and the RC matrix. Their results are in agreement with the findings reported by Portugal et al. ${ }^{91}$ In another study by Arthanareeswaran et al. ${ }^{79}$ the results showed that the water content of blended $\mathrm{CA} /$ silica membranes was related to the hydrophilicity of the membrane. The water content increased due to the detachment of silica from the polymer chains, which caused interface voids and led to larger pore sizes on the membrane and an accelerated water uptake in the pores.

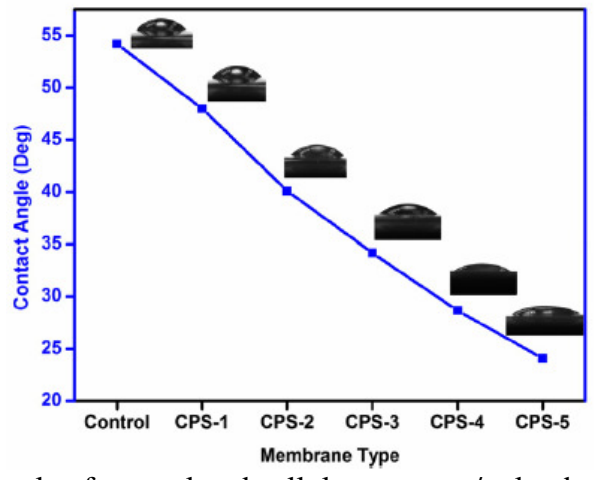

Figure 5: Contact angle of control and cellulose acetate/polyethylene silica membrane

Song et al $^{76}$ studied the characteristics of ultrafiltration membranes fabricated from polysulfone and polymer-grafted silica nanoparticles. The evaluation was based on five 
different membrane compositions: polysulfone (PSf) membrane, PSf/silica, PSf incorporating silica grafted with poly(vinyl alcohol) (PVA), poly(1-vinylpyrrolidone) (PVP), and poly(1vinylpyrrolidone-co-acrylonitrile) $\quad(\mathrm{P}(\mathrm{PV}-\mathrm{AN}))$. The results showed that the water flux of the PSf/silica membrane was slightly higher than that of the PSf membrane, while the membranes with grafted silica achieved about three times higher water flux than that of the PSf membrane. PSf is not miscible with PVA, but it is miscible with $\mathrm{P}(\mathrm{VP}-\mathrm{AN})$, and PVP appeared to be on the edge of the miscibility window. The miscibility showed better dispersion of silica particles in the PSf matrix, thus the PSf/P(VN-AN)-silica membrane exhibited the highest level of water flux amongst the membranes. In another similar study, ${ }^{92}$ cellulose composite membranes were prepared using suspensions of cellulose nanofibres, silica nanoparticles and polyamideamine-epichlorohydrin (PAE) via filtration. The results obtained revealed that the membranes prepared with nanofibres showed high flux, as compared with the other composite membranes. The pore size was controlled by the addition of silica. In another study, Wang et al..$^{93}$ investigated the effect of metal oxide particles in cellulose acetate membranes for the pervaporation separation of methanol/methyl tert-butyl ether mixtures. The $\mathrm{CA}$ membranes blended with metal oxides $\left(\mathrm{Al}_{2} \mathrm{O}_{3}\right.$ and $\left.\mathrm{ZnO}\right)$ improved the permeation flux and the separation of methanol/methyl tertbutyl ether. When compared to the pure CA membrane, the highest flux of the membrane filled with $\mathrm{Al}_{2} \mathrm{O}_{3}$ and $\mathrm{ZnO}$ was improved to $95.5 \%$ and $111 \%$, respectively.

Raabe $e t a l{ }^{84}$ evaluated the impact of different factors on the deposition of silica nanoparticles on cellulose fibers. The deposition of silica nanoparticles was carried out via the sol-gel process of TEOS precursor at four reaction times $(2,12,18$ and $24 \mathrm{~h})$. The results showed that the deposition of $\mathrm{SiO}_{2}$ nanoparticles decreased the hydrophilic capacity of cellulose fibers. Furthermore, the reaction of $18 \mathrm{~h}$ revealed low moisture absorption, between $12.3 \%$ and $13.0 \%$, which confirmed the formation of a uniform silica coating layer on the cellulosic fiber surface, compared to the other samples. The surface wettability of the prepared membrane showed a decrease in contact angle from $78.7^{0}$ to $61.5^{0}$ through the addition of silica from $0.05 \mathrm{wt} \%$ to $0.5 \mathrm{wt} \%$ on the PSf membrane. This indicated an improvement in the hydrophilicity of the membrane. Meer et al. ${ }^{87}$ prepared PS/silica nanocomposites coated with different silica nanoparticles contents. The study reported that coating with 4 wt $\%$ silica increased membrane thickness and led to a decline in water vapour permeation. This was related to the deposited silica nanoparticles, which penetrated into the cellulose matrix and blocked interspaces and cavities.

\section{Thermal properties}

According to the literature, the thermal stability of silica/cellulose nanocomposites increases with the addition of silica nanoparticles. In a study by Feng et al. ${ }^{94}$ the results showed that the silica/cellulose composite had less weight loss, as compared to the neat cellulose matrix. The addition of silica to the cellulose matrix resulted in an increase in the degradation temperature of the composites. Xie et $a l^{78}$ reported improved thermal properties of the cellulose hybrid composite in the presence of silica. The thermal plot analysis of cellulose/silica nanocomposites showed an order of high to small endothermic peaks, with increasing silica content and estimated that there was an interaction between silica and cellulose. This phenomenon showed that organic/inorganic nanocomposites exhibit not only the thermal properties of the inorganic components, but also the thermal properties of the organic polymer. Sheykhnazari et al..$^{95}$ conducted a study on bacterial cellulose (BC) composites loaded with silica nanoparticles. The TGA results showed that all the $\mathrm{BC} /$ silica composites were thermally stable, as compared to pure BC. The sample composite filled with $3 \mathrm{wt} \%$ silica showed strong thermal stability, while the sample containing $7 \mathrm{wt} \%$ showed higher degradation temperature, as compared to pure BC and other composite materials. Raabe et al. $^{84}$ evaluated the effect of reaction factors on deposited silica nanoparticles on cellulose fibers. The results showed that silica nanoparticles bonded to the surface of the cellulose matrix and were able to improve the thermal stability of the composites, increasing the onset degradation temperature.

\section{CONCLUSION}

Polymer nanocomposites are the most widely investigated materials in the world. They are the promising materials of the future for attaining sustainability, due to the unique properties they offer. Even so, there is little information known 
with regard to metal oxide/cellulose nanocomposites designed for water treatment and their benefits to the environment and the society. The high cost of effective application methods for water treatment could be reduced by making use of cellulose membranes, due to their properties, such as hydrophilicity, thermal stability, and mechanical stability. Moreover, incorporating silica could be the best move to improve the performance of composite membranes.

The mechanical properties of cellulose reinforced with silica display promising results for low filler content (usually below 6\%), with improvements in tensile strength and Young's modulus. The improvements are attributed to good dispersion and enhanced efficiency of the stress transfer mechanism between the silica and the cellulose. At high concentration, the silica particles become agglomerated, negatively affecting the properties of the membranes. The morphological properties of the silica/cellulose nanocomposites are strongly dependent on the synthesis method employed. The present review showed that silica particles can improve the hydrophilicity, water content and permeability of polymeric membranes at low filler content. An increase in the water content causes interface voids and leads to larger pore sizes. The thermal stability of silica/cellulose nanocomposites generally increases with the addition of silica nanoparticles at low filler content. The addition of silica to the cellulose matrix results in an increase in the onset degradation temperature of the composites and their thermal stability.

ACKNOWLEDGMENT: The authors would like to acknowledge the support in the form of resources from the University of Zululand.

\section{REFERENCES}

1 Z. Hua, W. Shishan and S. Jian, Chem. Rev., 9, 3893 (2008), https://doi.org/10.1021/cr068035q

2 R. Roy, R. A. Roy and D. M. Roy, Mater. Lett., 4, $323 \quad$ (1986), https://doi.org/10.1016/0167577X(86)90063-7

3 L. Petersson and K. Oksman, Compos. Sci. Technol., $\quad$ 66, $2187 \quad$ (2006), https://doi.org/10.1016/j.compscitech.2005.12.010

4 T. E. Motaung and L. Z. Linganiso, Int. J. Plast. Technol., $\quad 22, \quad 185 \quad$ (2018), https://doi.org/10.1007/s12588-018-9219-6

5 F. Hussain, M. Hojjati, M. Okamoto and R. E. Gorga, J. Compos. Mater., 40, 1575 (2006), https://doi.org/10.1177/0021998306067321
6 E. Ruiz-Hitzky, P. Aranda, M. Darder and M. Ogawa, Chem. Soc. Rev., 40, 801 (2011), https://doi.org/10.1039/c0cs00052c

7 H. M. Azeredo, Food Res. Int., 42, 1240 (2009), https://doi.org/10.1016/j.foodres.2009.03.019

${ }^{8}$ C. B. Murray, C. R. Kagan and M. G. Bawendi, Annu. Rev. Mater. Sci., 30, 545 (2000), https://doi.org/10.1146/annurev.matsci.30.1.545

9 E. Reverchon and R. Adami, J. Supercrit. Fluids, 37, 1

(2006), https://doi.org/10.1016/j.supflu.2005.08.003

10 G. Kickelbick, Prog. Polym. Sci., 28, 83 (2003), https://doi.org/10.1016/S0079-6700(02)00019-9

11 Y. Habibi, L. A. Lucia and O. J. Rojas, Chem. Rev., 110, 3479 (2010), https://doi.org/10.1021/cr900339w

12 J. Xu, E. F. Krietemeyer, V. M. Boddu, S. X. Liu and W. C. Liu, Carbohyd. Polym., 192, 202 (2018), https://doi.org/10.1080/02773813.2017.1411368

13 S. Collazo-Bigliardi, R. Ortega-Toro and A. C. Boix, Carbohyd. Polym., 191, 205 (2018), https://doi.org/10.1016/j.carbpol.2018.03.022

14 M. Kabsch-Korbutowicz and A. Urbanowska, Environ. Prot. Eng., 3, $125 \quad$ (2010), https://doi.org/10.1016/S0011-9164(04)90025-2

15 S. Leong, A. Razmjou, K. Wang, K. Hapgood, X. Zhang et al., J. Membr. Sci., 472, 167 (2014), https://doi.org/10.1016/j.memsci.2014.08.016

16 A. G. Fane, R. Wang and M. X. Hu, Angew. Chem. Int. $\quad$ Ed., $\quad \mathbf{5 4}, \quad 3368 \quad$ (2015), https://doi.org/10.1002/anie.201409783

17 A. Ahmad, S. Waheed, S. M. Khen, S. Gul, M. Shafiq et al., Desalination, 355, 1 (2015), https://doi.org/10.1016/j.desal.2014.10.004

18 G. Athanareeswaran, T. K. Sriyamuna and D. M. Raajenthirem, Sep. Purif. Technol., 64, 38 (2008), https://doi.org/10.1016/j.seppur.2008.08.010

19 M. H. D. Othman, S. K. Hubadilliah, M. R. Adam, A. F. Ismail, M. A. Rahman et al., in "Current Trends and Future Developments on (Bio-) Membranes", edited by A. Basile and K. Ghasemzadeh, Elsevier, 2017, Chapter 7, pp. 157-180, https://doi.org/10.1016/B978-0-444-63866-3.00007-8

20 L. Zoua, I. Vidalis, D. Steele, A. Michelmore, S. P. Low et al., J. Membr. Sci., 369, 420 (2011), https://doi.org/10.1016/j.memsci.2010.12.023

21 R. Abedini, S. M. Mousavi and R. Aminzadeh, Desalination, 277, $40 \quad$ (2012), https://doi.org/10.1016/j.desal.2011.03.089

22 R. P. Castro, Y. Cohen and H. G. Monbouquette, J. Membr. Sci., 115, $179 \quad$ (1996), https://doi.org/10.1016/0376-7388(96)00019-1

23 I. Gabrielii, P. Gatenholm, W. G. Glasser, R. K. Jain and L. Kenne, Carbohyd. Polym., 43, 367 (2000), https://doi.org/10.1016/S0144-8617(00)00181-8

24 J. J. Maya and T. Sabu, Carbohyd. Polym., 71, 343 (2008), https://doi.org/10.1016/j.carbpol.2007.05.040

25 A. Kaushik, M. Singh and G. Verma, Carbohyd. $\begin{array}{llll}\text { Polym., } & \text { 82, } & 337 & \text { (2010), }\end{array}$ https://doi.org/10.1016/j.carbpol.2010.04.063 
26 D. J. Gardner, G. S. Oporto, R. Mills and M. A. S. A. Samir, J. Adhes. Sci. Technol., 22, 545 (2012), https://doi.org/10.1163/156856108X295509

27 D. J. Gardner, G. S. Oporto and R. Mills, J. Adhes. Sci. Technol., 22, $545 \quad$ (2012), https://doi.org/10.1163/156856108X295509

28 C. Yamane, T. Aoyagi, M. Ago, K. Sato, K. Okajima et al., Polymer J., 38, 819 (2006), https://doi.org/10.1295/polymj.PJ2005187

${ }^{29}$ History of Reverse Osmosis Filtration, 2015, www.freedrinkingwater.com/reverse-

osmosis/knowledge-base/history-of-reverse-osmosisfiltration.htm

30 A. Pagidi, Y. L. Thuyavan, G. Arthanareeswaran, A. F. Ismail, J. Jaafar et al., J. Appl. Polym. Sci., 132, 416 (2014), https://doi.org/10.1002/app.41651

31 B. Thaci, S. Gashi, N. Daci, M. Daci and A. Dylhasi, Environ. Prot. Eng., 41, 53 (2015), https://doi.org/10.5277/epe150105

32 N. Ghaemi, S. S. Madaeni, A. Alizadeh, P. Daraei, V. Vatanpour et al., Desalination, 290, 99 (2012), https://doi.org/10.1016/j.desal.2012.01.013

33 L. A. N. El-Din, A. El-Gendi, N. Ismail, K. A. Abed and A. L. Ahmed, J. Ind. Eng. Chem., 26, 259 (2015), https://doi.org/10.1016/j.jiec.2014.11.037

34 S. Velu, K. Rambabu and I. Muruganandam, J. Chem. Pharm. Res., 5, 1418 (2013), https://doi.org/10.1002/app.41651

35 C. H. Worthley, K. T. Constantopoulos, M. GinicMarkovic, E. Markovic and S. Clarke, J. Membr. Sci., 431, 62

(2013), https://doi.org/10.1016/j.memsci.2012.12

36 R. V. Rodriguez, M. E. Montero-Caberera, H. E. Esparza-Ponce, E. F. Herrera-Peraza and M. I. Ballinas-Casarrubias, Appl. Radiat. Isot., 70, 872 (2012), https://doi.org/10.1016/j.apradiso.2012.01.017

37 M. Sile-Yuksel, B. Tas, D. Y. Koseoglu-Imer and I. Koyuncu, Desalination, 347, $120 \quad$ (2014), https://doi.org/10.1016/j.desal.2014.05.022

38 A. Y. Booshehri, R. Wang and R. Xu, Chem. Eng. J., 262, 999 (2015), https://doi.org/10.1016/j.cej.2014.09.096

39 S. B. Khan, K. A. Alamry, E. N. Bifari, A. M. Asiri, M. Yasir et al., J. Ind. Eng. Chem., 24, 266 (2015), https://doi.org/10.1016/j.jiec.2014.09.040

40 H. Bai, Z. Liu and D. D. Sun, Appl. Catal. B, 25, 571 (2012), https://doi.org/10.1016/j.apcatb.2011.11.

41 F. Ahmed, C. M. Santos, J. Mangadlao, R. Advincula and D. F. Rodrigues, Water Resour., 47, 3966

(2013), https://doi.org/10.1016/j.watres.2012.10.055

42 J. Meng, X. Zhang, L. Ni, Z. Tang, Y. Zhang et al., Desalination, $\quad 359, \quad 156 \quad$ (2015), https://doi.org/10.1016/j.desal.2014.12.032

43 T. Matsoukas and E. Gulari, J. Colloid Interface Sci., 132, 21 (1989), https://doi.org/10.1016/00219797(89)90210-5
44 G. H. Bogush, M. A. Tracy and C. F. Zukoski, J. Non-Cryst. Solids, 104, $95 \quad$ (1988), https://doi.org/10.1016/0022-3093(88)90187-1

45 G. H. Bogush and C. F. Zukoski, J. Colloid Interface $\quad$ Sci., $\quad \mathbf{1 4 2 ,} \quad 19 \quad$ (1991), https://doi.org/10.1016/0021-9797(91)90029-8

46 T. T. Y. Tan, S. Liu, Y. Zhang, M. Y. Han and S. T. Selvan, Comprehens. Nanosci. Technol., 5, 399 (2011), https://doi.org/10.1016/B978-0-12-3743961.00045-3

47 J. D. Wright and N. A. J. M. Sommerdijk, in "Powder Metallurgy", edited by L. Dobrzanski, Gordon and Breach Science Publishers, 2001, https://doi.org/10.5772/61469

48 V. Maneeratana, Alkoxide-Based Precursors for Direct Electrospinning of Alumina Fibers, University of Florida, 2007, https://doi.org/10.3390/polym11050839

49 I. A. Rahman and V. Padavettan, J. Nanomater., 2012 , ID 132424

(2012), https://doi.org/10.1155/2012/132424

50 I. A. Rahman, P. Vejayakumaran, C. S. Sipaut, J. Ismail and C. K. Chee, Ceram. Int., 34, 2059 (2008), https://doi.org/10.1016/j.ceramint.2007.08.014

51 S. Parida, S. Dash, S. Patel and B. K. Mishra, $A d v$. Colloid Interface Sci., 121, 77 (2006), https://doi.org/10.1016/0021-9797(75)90111-3

52 V. M. Gunko, E. F. Voronin and L. V. Nosach, J. Colloid Interface Sci., 355, $300 \quad$ (2011), https://doi.org/10.1016/j.jcis.2010.12.008

53 W. Stober, A. Fink and E. Bohn, J. Colloid Interface Sci., $\quad \mathbf{2 6}, \quad 62 \quad$ (1968), https://doi.org/10.1016/0021-9797(68)90272-5

54 Y. D. Glinka, S. H. Lin and Y. T. Chen, Phys. Rev., 66, $5404 \quad$ (2002), https://doi.org/10.1103/PhysRevB.66.035404

55 M. C. Neves, T. Trindade and M. Peres, Mater. Sci. Eng., 25, 654 (2005), https://doi.org/10.1016/j.msec.2005.06.019

56 I. A. Rahman, M. Jafarzadeh and C. S. Sipaut, $J$. Sol-Gel Sci. Technol., 50, $328 \quad$ (2009), https://doi.org/10.1007/s10971-009-1958-6

57 H. Althues, J. Henle and S. Kaskel, Chem. Soc. Rev., 36, $\quad 1454$ (2007), https://doi.org/10.1039/B608177K

58 M. K. D. Rambo, A. L. Cardoso, D. B. Bevilaqua, T. M. Rizzetti, L. A. Ramos et al., J. Agron., 10, 99 (2011), https://doi.org/10.3923/ja.2011.99.104

59 J. Shim, P. Velmurugan and B. Oh, J. Ind. Eng. Chem., $\quad 30, \quad 249 \quad$ (2015), https://doi.org/10.1016/j.jiec.2015.05.029

60 P. Velmurugan, J. Shim, K. Lee, S. M. Cho, S. Lim et al., J. Ind. Eng. Chem., 29, 298 (2015), https://doi.org/10.1016/j.jiec.2015.04.009

61 J. J. Kellar, "New Markets/New Horizons", SME, 2006, https://doi.org/10.1016/j.proche.2012.06.010

62 B. G. Trewyn, I. I. Slowing, S. Giri, H. T. Chen and V. S. Y. Lin, Acc. Chem. Res., 40, 846 (2007), https://doi.org/10.1021/ar600032u 
63 S. Azlin-Hasim, M. C. Cruz-Romero, M. A. Morris, S. C. Padmanabhan, E. Cummins et al., Food Bioprocess Technol., 9, 1661 (2016), https://doi.org/10.1007/s11947-016-1745-7

64 F. Chigondo, P. Shoko, B. C. Nyamunda, U. Guyo and M. Moyo, Int. J. Sci. Technol. Res., 6, 2277 (2013), www.ijstr.org/final-print/june2013/MaizeStalk-As-Reinforcement-In-Natural-Rubber-

Composites.pdf

65 W. Sujaritjun, P. Uawongsuwan, W. Pivsa-Art and H. Hamada, Energ. Procedia, 34, 664 (2013), https://doi.org/10.1016/j.egypro.2013.06.798

66 O. Faruk and M. Sain, "Biofiber Reinforcements in Composite Materials", Woodhead Publishing, 2014, pp. 454, https://doi.org/10.1016/C2013-0-16470-7

67 B. Zhao and W. Brittain, Prog. Polym. Sci., 25, 677 (2000), https://doi.org/10.1016/S0079-6700(00)000125

68 S. Liu, T. Yu, N. Hu, R. Liu and X. Liu, Colloid. Surf. A: Physicochem. Eng. Asp., 439, 159 (2013), https://doi.org/10.1016/j.colsurfa.2012.11.020

69 D. W. Lee and B. R. Yoo, J. Ind. Eng. Chem., 20, 3947 (2014), https://doi.org/10.1016/j.jiec.2014.08.004

70 H. Wang, P. Xu, W. Zhong, L. Shen and Q. Du, Polym. Degrad. Stabil., 87, 319 (2015), https://doi.org/10.1016/j.polymdegradstab.2004.08.015 71 D. W. Lee and B. R. Yoo, J. Ind. Eng. Chem., 38, 1 (2016), https://doi.org/10.1016/j.jiec.2016.04.016

72 G. Liu, M. Cai and F. Zhou, J. Phys. Chem. B, 118 , 4920 (2014), https://doi.org/10.1021/jp500074g

73 A. A. Chuiko and Y. I. Gorlov, "Silica Surface Chemistry. Surface Structure, Active Centers, Sorption Mechanisms", Naukova Dumka, Kiev, 1992

74 D. W. Sindorf and G. E. Maciel, J. Am. Chem. Soc., 105, $1487 \quad$ (1983), https://doi.org/10.1021/acs.chemmater.5b02801

75 J. P. Reddy, A. V. Rajulu, J. Rhim and J. Seo, Cellulose, 25, $7153 \quad$ (2008), https://doi.org/10.1007/s10570-018-2059-x

76 H. J. Song, Y. J. Jo, S. Kim, J. Lee, C. K. Kim et al., J. Membr. Sci., 466, $173 \quad$ (2014), https://doi.org/10.1016/j.memsci.2014.04.053

77 A. A. Ashori, S. Sheykhnazari, T. Tabarsa, A. Shakeri and M. Golalipour, Carbohyd. Polym., 90, 413 (2012), https://doi.org/10.1016/j.carbpol.2012.05.060

78 K. Xie, Y. Yu and Y. Shi, Carbohyd. Polym., 78, 799

(2009),

https://doi.org/10.1016/j.carbpol.2009.06.019

79 G. Arthanareeswaran, P. Thanikaivelan, K. Srinivasn, D. Mohan and M. Rajendran, Eur. Polym. J., 40, $2153 \quad$ (2004), https://doi.org/10.1016/j.eurpolymj.2004.04.024

80 C. Wu, M. Zhang, M. Romg and K. Friedrich, Compos. Sci. Technol., 65, 635 (2005), https://doi.org/10.1016/j.compscitech.2005.05.026

81 P. Wojciechowska, Z. Flotynowicz and M. Wowicki, Polymer, 58, 7 (2013), https://doi.org/10.14314/polimery.2013.543
82 S. A. Ibrahim and M. Z. Sultan, Egypt. J. Chem., 62, 131 (2019), https://www.ejchem.journals.ekb.eg > article_13442

83 P. Neto, Compos. Sci. Technol., 68, 1088 (2008), https://doi.org/10.1016/j.compscitech.2007.03.001

84 J. Raabe, A. S. Fonseca, L. Bufalino, C. Ribeirob, M. A. Martins et al., Carbohyd. Polym., 114, 424 (2014), https://doi.org/10.1016/j.carbpol.2014.08.042

${ }^{85}$ H. S. Barud, R. M. N. Assuncao, M. A. U. Martines, J. Dexpert-Ghys, R. F. C. Marques et al., J. Sol-Gel Sci. Technol., 46, 363 (2008), https://doi.org/10.1007/s10971-007-1669-9

${ }^{86}$ R. J. B. Pinto, P. A. A. P. Marques, A. M. BarrosTimmons, T. Trindade and C. P. Neto, Compos. Sci. Technol, $\quad \mathbf{6 8}, \quad 1088 \quad$ (2008), https://doi.org/10.1016/j.compscitech.2007.03.001

${ }^{87}$ S. Meer, A. Kausar and T. Iqbal, Polym. Plast. Technol. Eng., 55, $826 \quad$ (2016), http://dx.doi.org/10.1080/03602559.2015.1103267

88 C. A. Ghiorghita, F. Bucatariu and E. S. Dragan, Cellulose Chem. Technol., 52, 663 (2018), http://www.cellulosechemtechnol.ro/pdf/CCT78(2018)/p.663-672.pdf

${ }^{89}$ P. P. Selakjani, M. Jahanshahi and M. Peyravi, $\begin{array}{llll}\text { Cellulose, 24, } & 1333 & \text { (2017), }\end{array}$ https://doi.org/10.1002/pc.24960

90 M. S. Muhamad, M. R. Salim, W. J. Lau, M. A. Yuzir and S. Yunus, Adv. Membr. Technol. Res., 74, 23 (2015), https://doi.org/10.11113/jt.v74.4856

91 I. Portugal, M. V. Dias, R. F. Duarte and D. V. Evtugui, J. Phys. Chem., 114, 4047 (2010), https://doi.org/10.1021/jp911270y

92 Varanasi, Z.-X. Low and W. Batchelor, Chem. Eng. J., $\quad \mathbf{2 6 5}, \quad 138 \quad$ (2015), https://doi.org/10.1016/j.cej.2014.11.085.

93 Y. Wang, L. Yang, G. Luo and Y. Dai, Chem. Eng. $\begin{array}{llll}J ., & \mathbf{1 4 6}, & 6 & \text { (2009), }\end{array}$ https://doi.org/10.1016/j.cej.2008.05.009

94 J. Feng, D. Leb, S. T. Nguyen, V. T. C. Nien, D. Jewell et al., Colloids Surf. A: Physicochem. Eng. Asp., 506 298 (2016), https://doi.org/10.1016/j.colsurfa.2016.06.052

95 S. Sheykhnazari, T. Tabarsa, A. Ashori and A. Ghanbari, Int. J. Biol. Macromol., 93, 672 (2016), https://doi.org/10.1016/j.ijbiomac.2016.09.035 